Article

\title{
Curative and Suppressive Activities of Essential Tea Tree Oil against Fungal Plant Pathogens
}

\author{
Moshe Reuveni ${ }^{1,2, *}$, Ethel Sanches ${ }^{3}$ and Marcel Barbier ${ }^{4}$ \\ 1 Shamir Research Institute, University of Haifa, Katzrin 12900, Israel \\ 2 STK Bio-Ag Technologies Ltd., Petach Tikva 4951447, Israel \\ 3 Centro de Investigación en Estructuras Microscópiacas, Escuela de Biología, University of Costa Rica, \\ San Pedro de Montes de Oca 11501-2060, Costa Rica; malezacha@gmail.com \\ 4 Soil and Water Department, University of Florida, Homestead, FL 33030-2309, USA; \\ marcelbarbier65@gmail.com \\ * Correspondence: mreuveni@research.haifa.ac.il
}

Received: 26 March 2020; Accepted: 21 April 2020; Published: 24 April 2020

Abstract: Timorex Gold based on the essential tea tree oil (TTO) derived from the Australian tea tree oil (Melaleuca alternifolia) plant has demonstrated high efficacy and a strong curative activity against black Sigatoka in banana and controlled it in stages 1, 2, 3, and 4 of disease development. Transmission electron microscope (TEM) examination of infected leaf sections treated with Timorex Gold revealed disruption of the fungal cell membrane and destruction of the fungal cell wall in disease development stages 4 and 5. Mineral oil and the fungicide difenoconazole, when applied alone, had no curative effect and did not disrupt the fungal cell wall or membrane, similar to the untreated control tissue. A single spray of Timorex Gold effectively controlled and suppressed powdery mildew in cucumber by causing the disappearance of $99 \%$ of established colonies recorded 1 or 2 days after the application and was effective for up to 8 days after application. Scanning electron microscope (SEM) examination of infected and Timorex Gold-treated leaves indicated strong shrinkage and disruption of fungal hyphae and conidial cells. The curative and suppressive modes of action of the Timorex Gold may explain its success in controlling both diseases.

Keywords: bio-fungicide; disease control; fungal cell wall; Melaleuca alternifolia; Mycosphaerella fijiensis; Sphaerotheca fuliginea; Timorex Gold

\section{Introduction}

Black leaf streak, also known as black Sigatoka disease, is caused by Pseudocercospora fijiensis (teleomorph Mycosphaerella fijiensis) Morelet and is considered the most damaging and costly disease of commercial bananas and plantains [1,2]. Damage caused by this disease significantly reduces the photosynthesizing area of the leaf, and fruit-yield losses can reach $50 \%$ through premature maturation-a very serious problem in fruit grown for export [1,3,4]. Black Sigatoka spreads rapidly globally, and causes extensive economic damage. The response involves intensive use of fungicides, up to 70 sprays/year, especially in Costa Rica, due to the development of resistance [1,5].

Powdery mildew, caused by Sphaerotheca fuliginea, is a widely distributed and destructive disease of greenhouse-grown and field-grown cucumbers. Disease control is generally achieved by the use of fungicidal chemicals, including sulphur and sterol biosynthesis inhibitors. The emergence of fungicide-insensitive variants of the pathogen has been reported [6].

One of the means currently employed for controlling Sigatoka and powdery mildew diseases is the use of chemical fungicides. However, their use increases production costs, aggravates health problems among workers, and carries the risk of stimulating selection for resistant fungal populations. Furthermore, these products contaminate the fruit and the environment. 
The global search for plant-protection solutions that are both environmentally safe and effective is driven by the need to supply food for the ever-growing world population, and the call for chemical load reduction is an important aspect of sustainable agriculture. The natural essential tea tree oil (TTO) derived from the Melaleuca alternifolia plant contains many components, mostly terpenes (p-cymene, terpinen-4-ol, terpinolene, 1, 8-cineole, $\alpha$-pinene, $\gamma$-terpinene), sesquiterpenes and their respective alcohol (monoterpene alcohol-terpineol) (7). It has a maximum content of $15 \%$ of 1,8 - cineole and a minimum content of $30 \%$ of terpinen-4-ol, which is the main active constituent of oil (7). The oil has been shown to be an effective antiseptic and bactericide [7-9], and more recently also an effective fungicide [10-12]. The natural fungicide Timorex Gold (22.3 EC W/V) was prepared based on TTO as an active ingredient, in order to enable the use an emulsified TTO on plant tissue 14]. This formulation was found effective against a broad range of plant-pathogenic fungi in numerous crops $[13,14]$.

Previous studies [15] showed that Timorex Gold exhibits high activity against black Sigatoka. Observations in banana plantations indicated that Timorex Gold controlled this disease in development stages 1,2,3, and 4, which are characterized by being yellowish in colour and with chlorotic lesions of black Sigatoka. Studies also demonstrated that Timorex Gold was effective in controlling cucumber powdery mildew [15-17].

In the present study we investigated the curative activity of Timorex Gold against $M$. fijiensis hyphae on banana leaves and its suppressive activity against powdery mildew in cucumber leaves. Very little information is available on the use of transmission or scanning electron microscopy (TEM and SEM) for studying such activities in these fungal pathogens. This situation prompted us to undertake the present study to investigate the direct effect of Timorex Gold in suppressing powdery mildew colonies, and its mode of curative activity against $M$. fijiensis hyphae when symptoms of black Sigatoka, in stages 4 to 5, are evident on banana leaves. Preliminary results on banana have been presented [18].

\section{Materials and Methods}

\subsection{Curative Activity against Black Sigatoka in Banana Fungicides}

Tea tree oil was used in all trials as an emulsifiable concentrated formulation (Timorex Gold, 22.3 EC W/V; STK Group, Petach Tikva, Israel). It was applied to bananas similarly to the way synthetic conventional fungicides are applied, with mineral oil, surfactants, and water. The sterol-inhibitor fungicide difenoconazole (Sico 25 EC; Syngenta, Basel, Switzerland) and the mineral oil Spraytex (Texaco) were tested alone, as standards for comparison.

\subsection{Curative Activity of Tea Tree Oil (TTO) in a Banana Plantation}

This evaluation was carried out on large-scale semi-commercial plots in Guápiles, Limón in Costa Rica, on cv. Gran Naine banana plants. Preliminary trials demonstrated a high curative activity of Timorex Gold against black Sigatoka (16). In the current study, stage 3 and 4 lesions with an average size of 2.7 and $4.4 \mathrm{~mm}$, respectively, were selected and circled on infected banana leaves. Three lesions of each stage on each leaf of six randomly selected plants were circled. The plants were treated with consecutive foliar applications of Timorex Gold at $0.4 \mathrm{~L} /$ ha as described above, at 5- to 7-day intervals starting on 16 January 2011. For comparison, an adjacent plot was treated using a commercial program that included synthetic systemic and protectant fungicides at a recommended rate for each fungicide and at similar intervals. Leaves were selected in a similar manner and stage 3 and 4 lesions were selected on each of six plants. The size of each circled lesion of each stage and on each leaf and plant and treatment was measured 57 days after the first application, when lesions reached stages 5 and 6 on plants treated according to the commercial program.

\subsection{Experimental Design and Sampling for Transmission Electron Microscopy (TEM)}

In June 2011, a trial was conducted at the Monreri Experimental Farm in La Rita, Guápiles, Limón, Costa Rica, on cv. Gran Naine banana plants. The applied treatments included: Timorex 
Gold at $0.4 \mathrm{~L} / \mathrm{ha}$; difenoconazole (Sico, Syngenta) at $0.4 \mathrm{~L} / \mathrm{ha}$; and the agricultural mineral oil Spraytex (Texaco) at $7 \mathrm{~L} / \mathrm{ha}$. Untreated plants served as controls. Timorex Gold and fungicides were each mixed with Spraytex mineral oil at a rate of $7 \mathrm{~L} /$ ha plus 1\% of NP-7 (Bayer CropScience) plus water, in order to provide a total sprayed volume of $23 \mathrm{~L} / \mathrm{ha}$. The mineral oil Spraytex was also applied alone. All foliar applications were performed using a Model SR 420 motor-blown sprayer (Stihl) calibrated to apply the mixture at a final volume rate of $23 \mathrm{~L} / \mathrm{ha}$. Each treatment consisted of a single plot of nine plants, without replicates. Twelve consecutive foliar sprays of each mixture were applied weekly, and specimens of banana leaves naturally infected with $M$. fijiensis were collected. Samples of stage 4 and stage 5 spots were obtained from the apical part of each collected specimen of leaves 10, 11 and 12 of 13-leaf plants. Twenty-five specimens of leaf tissue exhibiting each stage of disease development were collected from each treatment.

\subsection{Transmission Electron Microscopy}

Samples of plant leaves exhibiting the various symptoms, which were collected from banana plants as described in the previous paragraph, were brought to the laboratory of the Research Center of Microscopic Structures (CIEMIC) of the University of Costa Rica and were prepared for examination by TEM. At least five samples of each stage and each treatment were prepared for examination, and at least five sections of each sample were examined.

The samples (approximately $3 \mathrm{~mm}$ long) were fixed in a $2.5 \%$ glutaraldehyde $/ 2 \%$ paraformaldehyde solution in $0.1 \mathrm{M}$ sodium phosphate buffer at $\mathrm{pH} 7.4$, for $4 \mathrm{~h} \mathrm{[19].} \mathrm{The} \mathrm{samples} \mathrm{were} \mathrm{then} \mathrm{rinsed} \mathrm{three}$ times in the same buffer, post-fixed on $2 \%$ osmium tetroxide $\left(\mathrm{OsO}_{4}\right)$ for $1 \mathrm{~h}$, rinsed three times with distilled water and then dehydrated with an acetone gradient $(30,50,70,90 \%$, and three times at $100 \%)$. The samples were then infiltrated with Spurr resin by transferring them to a 1:1 acetone:resin solution and then to $100 \%$ resin. Inclusion and polymerization of the resin were performed at $60^{\circ} \mathrm{C}$ for $12 \mathrm{~h}$. We used a Leica Reichert Ultracut ultramicrotome (Leica Reichertfor) for obtaining ultrathin 70-90 nm sections of the samples. The samples were then treated with uranyl acetate ( $4 \%$ in ethanol) and lead hydroxide, to improve contrast. The samples were examined with a H-7100 TEM (Hitachi) at the ICBR Laboratory, in the Microbiology Science building at the University of Florida in Gainesville.

\subsection{Suppression of Powdery Mildew in Cucumber}

Cucumber plants (Cucumis sativus cv. Hassan) were grown in a greenhouse in 10-cm diameter plastic pots containing a mixture of peat, vermiculite and soil $(1: 1: 1, v / v)$. The plants were watered to saturation twice per week using a $0 \%-1 \%$ 20-20-20 (N-P-K) fertilizer solution. Plants with four to five expanded true leaves were used in all experiments.

\subsection{Pathogen Maintenance, Inoculation and Chemical Treatments}

An isolate of Sphaerotheca fuliginea was obtained from a local greenhouse and subsequently maintained on cucumber plants by mass spore transfer. Inoculum was obtained from freshly sporulating leaves 9-12 days after inoculation. Conidia were gently brushed into a small quantity of distilled water containing two drops of Tween-20 and counted using a hemocytometer to give a suspension of $2.5 \times 10^{4}$ conidia $/ \mathrm{mL}$. The upper surfaces of all the leaves of each plant were inoculated by spraying them uniformly with a conidial suspension delivered from a glass hand sprayer. After inoculation, the plants were incubated in a dew chamber at $20^{\circ} \mathrm{C}$ in the dark, for $20-24 \mathrm{~h}$. The plants were returned to the greenhouse conditions $\left(16-20{ }^{\circ} \mathrm{C}\right.$ during the night and $22-32{ }^{\circ} \mathrm{C}$ during the day, $14 \mathrm{~h}$ of light per day), after which disease developed.

The percentage of the infected area of each leaf and each plant was recorded 8-12 days after inoculation, when powdery mildew colonies on the foliage were fully developed. The upper surface of each leaf was sprayed with 1-2 mL of various concentrations of freshly prepared Timorex Gold or water using a glass hand sprayer. In some of the experiments, the liquid sulfur Heliosulfur (70 SC, Action-Pin, France) was tested for comparison. After treatment, the plants were arranged in a 
completely randomized design and kept in a growth chamber $\left(25^{\circ} \mathrm{C}\right.$ and $14 \mathrm{~h}$ light/day, $\left.100 \mu \mathrm{E} \cdot \mathrm{m}^{-2} \cdot \mathrm{s}^{-1}\right)$. Disease was recorded on various days after treatment, as described above.

\subsection{Growth Chamber Experiments}

In the first experiment, the upper surface of each of five leaves of each of four greenhouse-grown plants bearing a relatively low severity of mildew was sprayed with either 0.2 or $0.5 \%(v / v)$ Timorex Gold or with water for comparison. Untreated plants served as controls. The percentage of infected leaf area on each leaf of each treated plant was recorded just before treatment. The plants were kept in a growth chamber $\left(25^{\circ} \mathrm{C}\right.$ and $\left.14 \mathrm{~h} \mathrm{light/day,} 100 \mu \mathrm{E} \cdot \mathrm{m}^{-2} \cdot \mathrm{s}^{-1}\right)$ and disease was recorded as mentioned above, one and seven days after treatment.

A similar experiment was conducted using infected cucumber plants bearing a relatively high severity of mildew. Plants were evaluated for disease severity and sprayed with 0.2 and $0.5 \%$ $(v / v)$ Timorex Gold, in a similar way to the manner described above. Untreated plants served as controls. The plants were then kept in a growth chamber and evaluated for disease one and six days after treatment.

Another type of experiment was undertaken in order to determine the effectiveness of re-application of Timorex Gold and its longevity in suppressing powdery mildew lesions. In this experiment, infected plants were evaluated for disease severity and sprayed with $0.25 \%, 0.5 \%$ and $1 \%(v / v)$ Timorex Gold and $0.5 \%(v / v)$ Heliosulfur as described above. Untreated plants served as controls. The plants were then kept in a growth chamber and disease was evaluated at various day intervals after treatments. At 11 days after the first application, when disease began to increase, both Timorex Gold and Heliosulfur were re-applied on the same plants at the same concentrations. Disease was evaluated again one and seven days after the second application. Five replicate plants, each containing four leaves, were used for each treatment.

\subsection{Disease Assessment}

The efficacies of the various treatments were determined by evaluating the percentage of each infected area of each leaf and each plant just before and at intervals after application. There were at least four plants per treatment and each experiment was repeated at least twice.

\subsection{Scanning Electron Microscopy (SEM) Examination of Powdery Mildew on Cucumber Leaf Samples}

Leaves were fixed with Trumps fixative (Electron Microscopy Sciences, Hatfield, PA, USA) and stored overnight at $4{ }^{\circ} \mathrm{C}$. Fixed leaves were processed with the aid of a Pelco BioWave laboratory microwave (Ted Pella, Redding, CA, USA). The samples were washed in 1X phosphate-buffered saline (PBS), pH 7.24, post-fixed with $2 \%$ buffered osmium tetroxide, water washed, dehydrated in a graded ethanol series 25\%, 50\%, 60\%, 75\%, 95\%, 100\% and critical point dried (Bal-Tec CPD030, Leica Microsystems, Bannockburn, IL). Dried samples were mounted on double-sided adhesive tabs on an aluminum specimen mount, Au/Pd sputter-coated (DeskV, Denton Vacuum, Moorestown, NJ, USA) and examined. High-resolution digital micrographs were achieved using a field-emission scanning electron microscope (S-4000, Hitachi High Technologies America, Inc. Schaumburg, IL, USA).

\section{Statistical Analysis}

Experiments with powdery mildew were conducted at least twice. The data from repeated experiments were combined for analysis because variance between experiments was homogeneous. Analysis of variance (ANOVA) using the SAS GLM (General Linear Model, SAS Institute, Inc., Cary, NC, USA) procedure was applied to the data. The Tukey-Kramer test was applied to determine whether differences between treatments were significant at $\alpha=0.05$. 


\section{Results}

\subsection{Curative Activity of Timorex Gold in Banana}

This evaluation was carried out on large-scale semi-commercial plots in Costa Rica. Preliminary trials demonstrated a high curative activity of Timorex Gold against black Sigatoka and controlled the disease in stages 1, 2, 3, and 4 (16). Results of this experiment showed that stage 3 and 4 lesions, with an average size of 2.7 and $4.4 \mathrm{~mm}$, respectively, became dark brown after treatment with Timorex Gold, and did not expand more than one $\mathrm{mm}$ beyond the size of the lesions at the beginning of the experiment, even 57 days after the first application (Table 1). Conversely, similar lesions on leaves, treated according to the commercial chemical fungicidal program, continued their normal development of black Sigatoka symptoms and reached a size of $10.8 \pm 1.5$ and $19.2 \pm 3.9 \mathrm{~mm}$ for stages 5 and 6 , respectively (Table 1 ).

Table 1. Curative activity of Timorex Gold against M. fijiensis in banana leaves.

\begin{tabular}{|c|c|c|}
\hline \multirow{2}{*}{ Treatment and Rate ${ }^{1}(\mathrm{~L} / \mathrm{ha})$} & \multicolumn{2}{|c|}{ Lesion Size $(\mathrm{mm}) \pm \mathrm{SE}$ and Development Stage of Black Sigatoka } \\
\hline & At Day $0^{2}$ & 57 Days after First Treatment ${ }^{3}$ \\
\hline Timorex Gold (0.4) & $2.7 \pm 0.3($ stage 3$)$ & $3.5 \pm 0.5($ Stage 3$)$ \\
\hline Timorex Gold (0.4) & $4.4 \pm 0.6$ Stage 4$)$ & $5.2 \pm 0.8($ stage 4$)$ \\
\hline Synthetic fungicides & $2.7 \pm 0.3$ Stage 3$)$ & $10.8 \pm 1.8($ stage 5$)$ \\
\hline Synthetic fungicides & $4.4 \pm 0.8($ stage 4$)$ & $19.2 \pm 3.9($ stage 6$)$ \\
\hline
\end{tabular}

${ }^{1}$ The plants were treated with consecutive foliar applications of Timorex Gold at $0.4 \mathrm{~L} /$ ha or with synthetic systemic and protectant fungicides at a recommended rate for each fungicide and at similar intervals; ${ }^{2}$ Stage 3 and 4 lesions were selected and circled on infected banana leaves as described in Materials and Methods; ${ }^{3}$ The size of each circled lesion of each stage and treatment was measured 57 days after the first application.

\subsection{TEM Examination of Samples from the Experimental Trial}

Examination of infected tissue samples exhibiting development stages 4-5 of black Sigatoka, from untreated control leaves and from those treated with mineral oil alone, showed no differences in fungal hyphae structure and content. Normal fungal cells with an intact cell membrane and cell wall were observed in both treatments, indicating that both had no curative effect (Figure 1, panels a and $b$ ). This resulted in great damage and death of plant cells due to normal fungal development in the leaf tissue (Figure 2, panels a and b). Analysis of leaf samples treated with the sterol biosynthesis inhibitor difenoconazole showed a normal content in the fungal cell, with an intact cell membrane but with a thick and apparently hardening cell wall, probably due to inhibition of ergosterol synthesis by this product (Figure 1c). However, a clear change in the fungal hyphal structure was observed in Timorex Gold-treated tissue: a relatively large number of the fungal hyphae (38\% on average) exhibited incomplete cell membranes and disrupted cell walls (Figure 3, panels a and b). Timorex Gold caused disruption of the fungal cell wall and cell membrane. This disruption of the membrane and cell wall altered the cellular osmolality and resulted in a breakdown of the cell wall that may lead to leakage of the cell contents, and cell death (Figure 4, panels a and b).
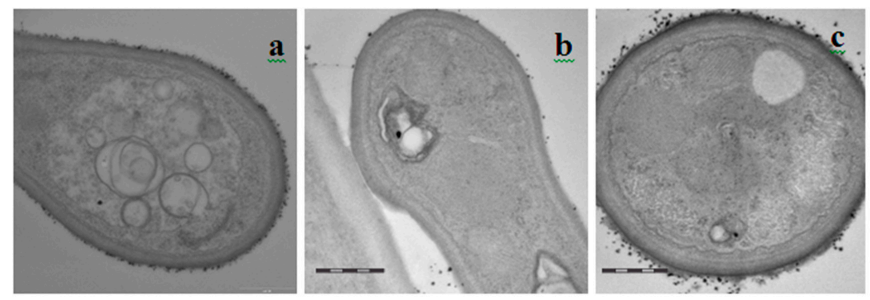

Figure 1. Longitudinal (panels a and b) and transverse (panel c) sections of fungal hyphae of M. fijiensis in the intracellular space of the mesophyll tissue of banana leaf of: control untreated (a); mineral oil-treated (b); and difenoconazole-treated (c) leaves (magnification ×50,000). 

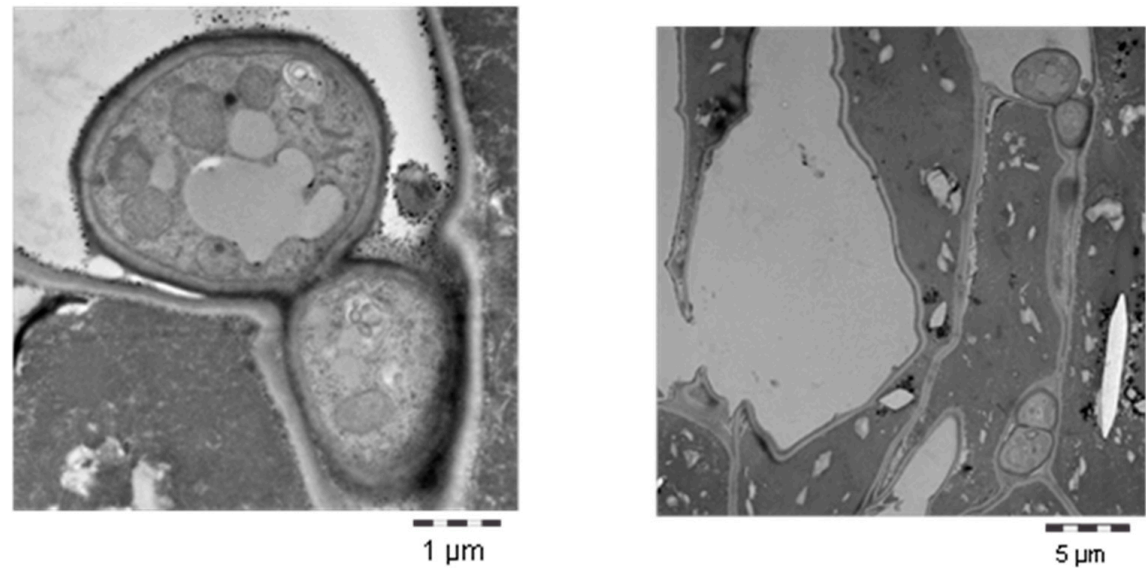

Figure 2. Panels a and b. A transverse section (left) of palisade tissue of a mineral oil-treated plant showing extensive damage and death of plant cells with several fungal hyphae of $M$. fijiensis in the intracellular space of banana leaf tissue at low magnification $(\times 3500)$; and (right) a higher magnification of of a typical fungal hypha of a section from the left panel $(\times 17,000)$.
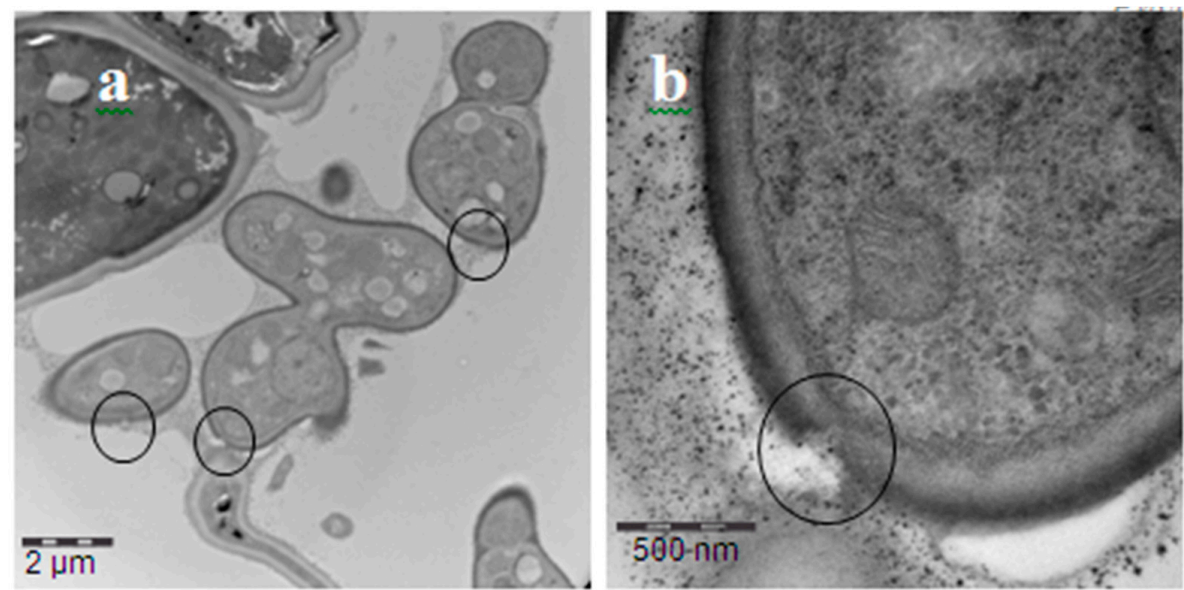

Figure 3. A section of fungal hyphae of $M$. fijiensis in the intracellular space of the mesophyll tissue of Timorex Gold-treated banana leaves: (a) at low magnification $(\times 8000)$; and $(\mathbf{b})$ at high magnification $(\times 50,000)$. Note the disruption and breakdown of the cell wall.
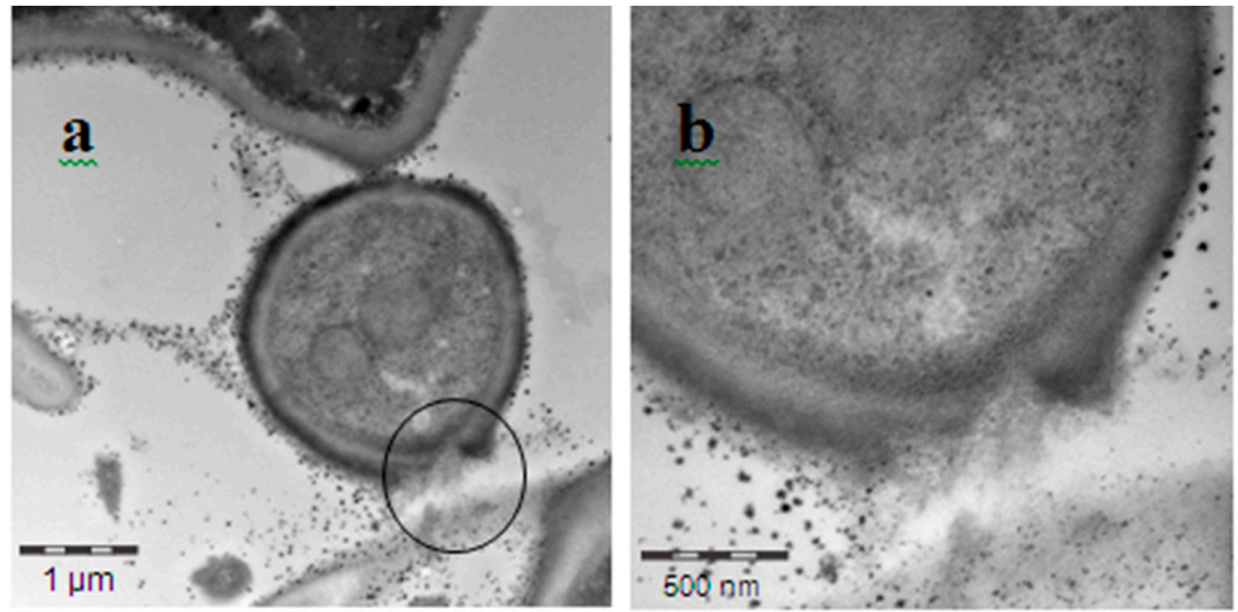

Figure 4. A section of fungal hyphae of $M$. fijiensis in the intracellular space of the mesophyll tissue of Timorex Gold-treated banana leaves: (a) at low magnification $(\times 20,000=\mathbf{a})$ and $(\mathbf{b})$ at high magnification $(\times 50,000)$. Note the destruction and breakdown of cell wall causing leakage of cell content. 


\subsection{Suppression of Powdery Mildew in Cucumber}

A single Timorex Gold spray on the upper surface of leaves with well-established powdery mildew colonies markedly suppressed the fungus and caused disappearance of powdery mildew lesions from infected foliage, as shown in Figure 5. Data presented in Tables 2 and 3 support these findings, where Timorex Gold significantly suppressed the fungus as recorded one or two days after application, regardless of the concentration used or the disease pressure on the surface of the leaves at the beginning of the experiment. An increase in disease level was observed at six or seven days after treatment, mainly in the second experiment on plants infected with high disease pressure at the beginning of the trial (Table 3). Spraying water only did not significantly affect the fungus (Table 2).
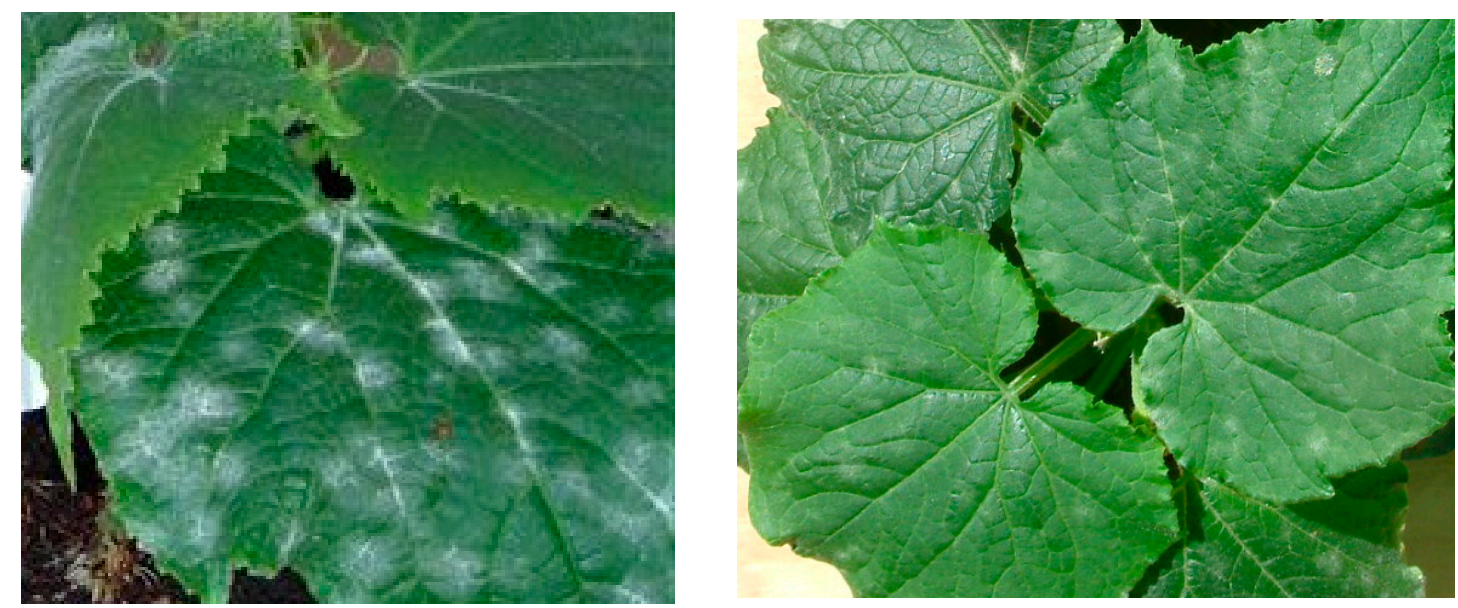

Figure 5. Suppression of powdery mildew colonies on cucumber leaf at one day post a single application of $0.5 \%$ Timorex Gold (right) or on a control untreated leaf (left). Note the disappearance of colonies on the surface of the treated leaf.

Table 2. Suppression of powdery mildew on cucumber plants by a single foliar Timorex Gold spray.

\begin{tabular}{cccc}
\hline \multirow{2}{*}{ Treatment and Concentration $(\boldsymbol{\%} \boldsymbol{v} / \boldsymbol{v})^{\mathbf{1}}$} & \multicolumn{3}{c}{$\%$ Infected Leaf Area On $^{\mathbf{2}}$} \\
\cline { 2 - 4 } & Day $\mathbf{0}$ & 1 Day & 7 Days \\
\hline Control untreated & $14.9 \mathrm{a}^{3}$ & $27.6 \mathrm{a}$ & $49.9 \mathrm{a}$ \\
Control一water treated & $13.6 \mathrm{a}$ & $22.7 \mathrm{a}$ & $45.6 \mathrm{a}$ \\
Timorex Gold 0.2 & $12.8 \mathrm{a}$ & $5.3 \mathrm{~b}$ & $6.6 \mathrm{~b}$ \\
Timorex Gold 0.5 & $12.5 \mathrm{a}$ & $2.3 \mathrm{~b}$ & $3.5 \mathrm{~b}$ \\
\hline
\end{tabular}

1 The upper surface of the leaves of four greenhouse-grown plants bearing low severity of mildew was sprayed with each of the treatments. ${ }^{2}$ The percentage of infected leaf area on five leaves of each treated plant as described in Materials and Methods was recorded at various days after spray. ${ }^{3}$ Means within columns followed by different letters are significantly different $(p<0.05)$ according to the Tukey-Kramer test.

Table 3. Suppression of powdery mildew on cucumber plants by a single foliar Timorex Gold spray.

\begin{tabular}{cccc}
\hline \multirow{2}{*}{ Treatment and Concentration $(\% \boldsymbol{v} / \boldsymbol{v})^{\mathbf{1}}$} & \multicolumn{3}{c}{ \% Infected Leaf Area on ${ }^{\mathbf{2}}$} \\
\cline { 2 - 4 } & Day $\mathbf{0}$ & 2 Days & 6 Days \\
\hline Control untreated & $58.9 \mathrm{a}^{3}$ & $70.7 \mathrm{a}$ & $73.1 \mathrm{a}$ \\
Timorex Gold 0.2 & $57.2 \mathrm{a}$ & $6.7 \mathrm{~b}$ & $22.8 \mathrm{~b}$ \\
Timorex Gold 0.5 & $56.7 \mathrm{a}$ & $0.6 \mathrm{~b}$ & $10.9 \mathrm{~b}$ \\
\hline
\end{tabular}

${ }^{1}$ The upper surface of the leaves of four greenhouse-grown plants bearing high severity of mildew was sprayed with each of the treatments. ${ }^{2}$ The percentage of infected leaf area on five leaves of each treated plant as described in Materials and Methods was recorded at various days after spray. ${ }^{3}$ Means within columns followed by different letters are significantly different $(p<0.05)$ according to the Tukey-Kramer test. 
In the third experiment, Heliosulfur and Timorex Gold were sprayed on diseased foliage and suppression of powdery mildew was recorded. The data presented in Figure 6 clearly demonstrate the suppressive activity of Timorex Gold after the first and second applications. The most significant suppressive effect, which was expressed as the disappearance of $99 \%-100 \%$ of the lesions, was recorded as early as one day after the first foliar spray and remained so up to 8 days later (Figure 6). When disease began to increase at 11 days after the first application, both products were re-applied at the same concentrations on the same plants. An almost complete reduction in the severity of powdery mildew was recorded one day after the second application and remained relatively low for six more days (Figure 6).

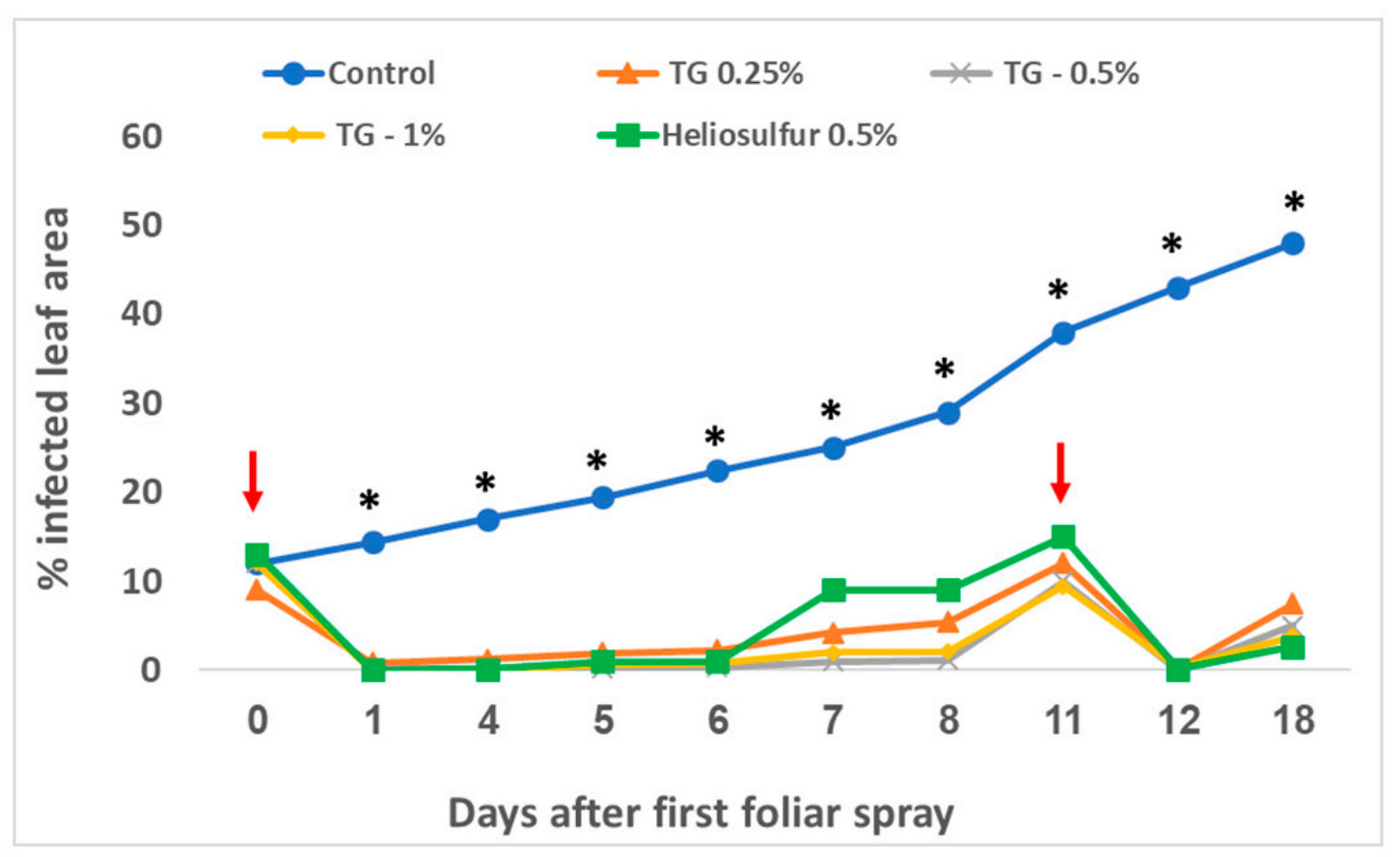

Figure 6. Suppression of powdery mildew colonies on cucumber leaves following application of Timorex Gold (TG) and Heliosulfur and the effect of re-application 11 days later. Treatments were applied on day 0 and percentage of infected leaf area was evaluated at intervals after the first application. Treatments were re-applied in the same manner on days 11 and the plants were evaluated at intervals afterwards. Arrows represent the application days. Asterisks over the control indicate significant differences $\left({ }^{*} p<0.01\right)$ according to the Tukey-Kramer test.

\subsection{SEM Examination of Powdery Mildew on Cucumber Leaf Samples}

Scanning electron microscope examination of tissue samples of both untreated control and Timorex Gold-treated samples was carried out on leaf samples taken $24 \mathrm{~h}$ after the foliar spray. A normal morphology of $S$. fuliginea hyphae and conidia was observed in the control untreated infected cucumber leaves (Figure $7 \mathrm{a}-\mathrm{c}$ ). Infected leaves exposed to a single application of Timorex Gold (Figure 7d-f) revealed considerable morphological changes to their hyphae. The changes in hyphal morphology indicated a strong shrinkage and disruption of fungal hyphae and conidial cells, including protoplast leakage and conidial destruction that were observed at low (d) and high (e) magnification. Conidial destruction is clearly evident at high (f) magnification. 

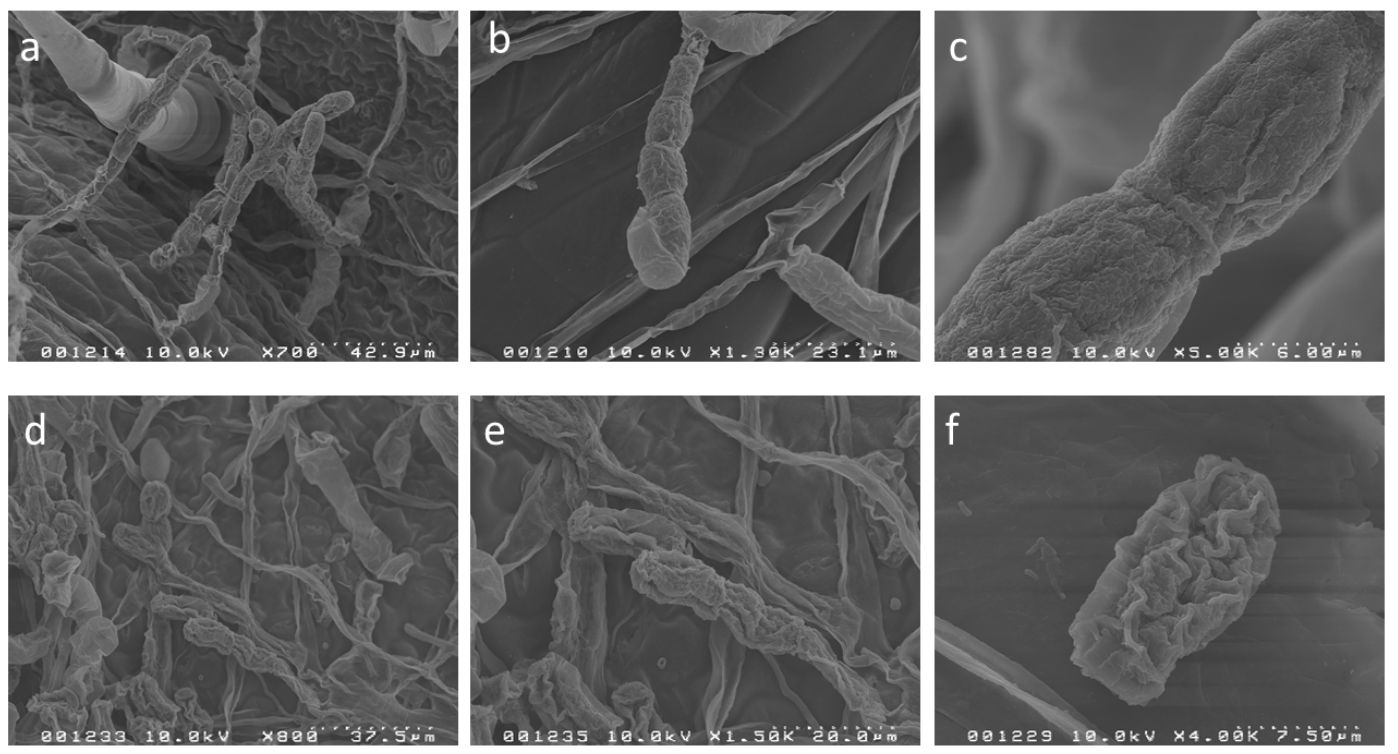

Figure 7. Scanning electron micrograph of hyphae and conidia of S. fuliginea of control untreated infected cucumber leaves: (a) at low magnification; (b) at high magnification; (c) normal with a complete smooth surface of the conidium at high magnification; $(\mathbf{d}-\mathbf{f})$ infected leaves exposed to a single application of Timorex Gold. Note alterations in hyphal morphology and shriveling and conidial destruction at low (d) and high (e) magnification and destroyed conidia at a high (f) magnification. Leaf samples for microscopy were taken $24 \mathrm{~h}$ post-application.

\section{Discussion}

We investigated ultrastructural morphological changes of M. fijiensis hyphae and S. fuliginea hyphae and conidia in order to determine the mode of curative and suppressive activities of Timorex Gold when symptoms of these fungal pathogens were evident on banana and cucumber leaves. Some researchers studied the development of $M$. fijiensis in banana leaves with either light or scanning electron microscopy $[19,20]$. However, to the best of our knowledge, no study has so far compared the curative activity of the Timorex Gold product with those of systemic fungicides and mineral oil.

Black Sigatoka is considered the most damaging and costly disease of bananas and plantains $[1,3,4]$, because its control accounts for $27 \%$ of the total production costs [1]. The TTO-based biofungicide Timorex Gold has demonstrated high efficacy against black Sigatoka disease in bananas $[15,21]$. At appropriate concentrations, Timorex Gold significantly inhibited germination of ascospors or lesion development on treated leaves, and limited the expansion of lesions caused by $M$. fijiensis $[15,22]$, and thus severely restricted the potential of $M$. fijiensis to infect plant tissue and cause disease. Once infection has occurred, suppression of fungal growth within the host tissue becomes an important disease-management objective.

The present study showed that Timorex Gold exhibited high curative activity against black Sigatoka. Unlike most other fungicides, which can only control black Sigatoka in stages 1 and 2, Timorex Gold controlled it at disease development stages 1, 2, 3 and 4. Stage 3 and 4 lesions that were treated with consecutive foliar applications of Timorex Gold became dark brown and showed almost no further expansion even 57 days after the first application (Table 1). This enables growers to use it even when the disease is already visible on banana leaves.

The fungicidal and antimicrobial activities of the essential TTO against fungal pathogens are derived from its ability to disrupt the permeability barrier presented by the membrane structures of living organisms [7-9]. In yeast cells and in isolated mitochondria of a plant extract of M. alternifolia components, it was found to disrupt cellular integrity, inhibit respiration and ion transport processes, and increase membrane permeability [7-9]. Our present results, obtained using transmission electron microscopy, confirm the ability of essential tea tree oil formulated as Timorex Gold to disrupt the 
permeability barrier of the membranes of phytopathogenic fungi and show that it can be used as an effective fungicide [10,11]. Timorex Gold disrupted the fungal cell membrane and cell wall of $M$. fijiensis at stage 4 or 5 of the fungal development in the intracellular space of the banana leaf mesophyll (Figures 3 and 4). This may explain why leaves infected with $M$. fijiensis at stage 4 of black Sigatoka development that were treated with Timorex Gold had fewer M. fijiensis fungal hyphae in the intracellular spaces of the mesophyll tissue than leaves treated using commercial programs based on synthetic systemic fungicides, including mancozeb, or untreated controls (unpublished data). This accounts for and confirms the high curative activity of Timorex Gold against black Sigatoka, which has been widely demonstrated on commercial banana plantations $[13,16]$. In the present study, this effect was not seen on any examined tissue treated with mineral oil alone. Such samples behaved similarly to control untreated tissue, indicating that it had no curative effect (Figure 1, panels a and b) and caused extensive damage and death of plant cells due to typical development of the fungus within the leaf tissue (Figure 2, panels a and b). The activity of the mineral oil is mainly fungistatic, and prevents spore germination and germ-tube growth of the Sigatoka pathogen [3]. Difenoconazole apparently stresses the fungal cell wall, probably by inhibition of ergosterol synthesis (Figure 1c). The mode of action of sterol biosynthesis inhibitors, including difenoconazole, has been investigated extensively [23]: they inhibit C-14 demethylation of lanosterol or 24-methylenedihydrolanosterol, a biosynthesis step that occurs during conversion of lanosterol to ergosterol, the final product of fungal cell wall sterol synthesis [22]. According to our present results, the mode of action of TTO is different from those of sterol-inhibiting fungicides. It disrupted the cell membrane and the cell wall. Disruption of cell wall structures has a profound effect on the growth and morphology of the fungal cell, often rendering it susceptible to lysis and death [24].

The fungal wall is a complex structure, typically composed of chitin, 1,3-b- glucan and 1,6-b-glucan, mannan and proteins, although the composition can vary markedly between fungal species [24]. The wall is a highly dynamic structure, subject to constant change, for example hyphal branching and septum formation during spore germination in filamentous fungi. Most of the fungal cell wall hydrolases that have been characterized to date exhibit chitinase or glucanase activity, and several of these enzymes also exhibit transglycosylase activity. They may, therefore, contribute to breakage and re-forming of bonds within and between polymers, leading to re-modeling of the cell wall during growth and morphogenesis [24]. The glucan and chitin cell wall components are synthesized on the plasma membrane, and are extruded into the cell wall space during this synthesis [24]. Thus, disruption of the regulation of glucanase and chitinase activities may lead to formation of inappropriate fungal cell wall hydrolases or excessive expression of glucanase and/or chitinase activities in the wall, leading to cell lysis [25]. We hypothesize that TTO may disrupt the synthesis of cell wall components in the cell membrane, thereby leading to cell wall lysis. Further biochemical studies are needed to confirm this hypothesis.

This study also demonstrated that the tea tree oil-based product Timorex Gold effectively suppressed powdery mildew development on cucumber plants. It was evident throughout the experiments that a single application of Timorex Gold was effective in suppressing the lesions from diseased foliage (Tables 2 and 3, Figures 5 and 6). Our microscopic observations (Figure 7) pointed to a direct effect of Timorex Gold on the mycelia and conidia, which were collapsed and exhibited irregular shapes. This was accompanied by significant shrinkage of hyphae, conidia and conidiophores exposed to Timorex Gold. A similar collapse of hyphal walls and shrinkage of conidia and conidiophores of S. fuliginea exposed to potassium bicarbonate or potassium phosphate has been observed previously $[26,27]$. This may be related to a direct effect of TTO against the fungus. Collapse and shriveling of hyphae was also observed when other pathogens were exposed to other essential oils $[28,29]$.

The efficiency of TTO-based Timorex Gold in suppressing powdery mildew on cucumber, as reported here, together with the high efficacy in controlling the fungus and other fungal pathogens $[10-12,15]$ and with the strong curative activity against $M$. fijiensis in banana as presented 
here, make it an important component for disease control in crop protection. This, together with the fact that it is a reliable eco-friendly bio-fungicide, with no residues, and that it can be a tool for managing resistance, make it an important component in plant disease control.

\section{Conclusions}

This study provides further novel information on the mode of activities of the Australian tea tree oil (TTO) against plant pathogens. The TTO-based product Timorex Gold disrupted the fungal cell membrane and cell wall of $M$. fijiensis at stages 4 or 5 of the fungal development in the intracellular space of the banana leaf mesophyll, which explains its strong curative activity. In addition, it effectively suppressed powdery mildew colonies on cucumber tissue by significant shrinkage of hyphae, conidia and conidiophores exposed to Timorex Gold. These together with the efficacy of TTO in controlling fungal pathogens make it an important component for disease control in crop protection.

Author Contributions: M.R., E.S. and M.B. planned the experiments and played roles in data collection and data analysis, M.R. played role in decision to publish and preparation of the manuscript.Funding: This work was funded by STK Bio-Ag Technologies. No specific grants were received. All authors have read and agreed to the published version of the manuscript.

Acknowledgments: We thank Karen L. Kelly and her team at the ICBR Laboratory, University of Florida, Gainesville FL, for their valuable assistance in the TEM and SEM work, and Ricardo and Rebecca Astua of the Monreri Laboratorio Agricola, and Fernando Ramirez, San Jose, Costa Rica, for their technical assistance.

Conflicts of Interest: The authors declare no conflicts of interest.

\section{References}

1. Marín, D.H.; Romero, R.A.; Guzmán, M.; Sutton, T.B. Black sigatoka: An increasing threat to banana cultivation. Plant Dis. 2003, 87, 208-222. [CrossRef] [PubMed]

2. Stover, R.H. Sigatoka leaf spots of bananas and plantains. Plant Dis. 1980, 64, 750-755. [CrossRef]

3. Stover, R.H. Disease management strategies and the survival of the banana industry. Annu. Rev. Phytopathol. 1986, 24, 83-91. [CrossRef]

4. Fullerton, R.A. Compendium of Tropical Fruit Diseases; APS: St. Paul, MN, USA, 1994.

5. Stover, R.H. Thirty years of changing control strategies: 1959-1989. In Proceedings of the 10th Annual Meeting ACORBAT, San Jose, Costa Rica, 28 March-1 April 1989.

6. Schepers, H.T.A.M. Decreased sensitivity of Sphaerotheca fuliginea to fungicides which inhibit ergosterol biosynthesis. Neth. J. Plant Pathol. 1983, 89, 185-187. [CrossRef]

7. Carson, C.F.; Hammer, K.A.; Riley, T.V. Melaleuca alternifolia (Tea Tree) oil: A review of antimicrobial and other medicinal properties. Clin. Microbiol. Rev. 2006, 19, 50-62. [CrossRef]

8. Carson, C.F.; Mee, B.J.; Riley, T.V. Mechanism of action of Melaleuca alternifolia (tea tree) oil on Staphylococcus aureus determined by time-kill, lysis, leakage, and salt tolerance assays and electron microscopy. Antimicrob. Agents Chemother. 2002, 46, 1914-1920. [CrossRef]

9. Cox, S.D.; Mann, C.M.; Markham, J.L.; Gustafson, J.E.; Warmington, J.R.; Wyllie, S.G. Determining the antimicrobial actions of tea tree oil. Molecules 2001, 6, 87-91. [CrossRef]

10. Shao, X.; Wang, H.; Xu, F.; Cheng, S. Effects and possible mechanisms of tea tree oil vapor treatment on the main disease in postharvest strawberry fruit. Postharvest Biol. Technol. 2013, 77, 94-101. [CrossRef]

11. Shao, X.; Cheng, S.; Wang, H.; Yu, D.; Mungai, C. The possible mechanism of antifungal action of tea tree oil on Botrytis cinerea. J. Appl. Microbiol. 2013, 114, 1642-1649. [CrossRef]

12. Yu, D.; Wang, J.; Shao, X.; Xu, F.; Wang, H. Antifungal modes of action of tea tree oil and its two characteristic components against Botrytis cinerea. J. Appl. Microbiol. 2015, 119, 1253-1262. [CrossRef]

13. Reuveni, M.; Barbier, M.; Viti, A.J. Essential tea tree oil as a tool to combat black Sigatoka in banana. Outlooks Pest Manag. 2020. [CrossRef]

14. Reuveni, M.; Neifeld, D.; Dayan, D.; Kotzer, Y. BM-608-A novel organic product based on essential tea tree oil for the control of fungal diseases in tomato O. Acta Hortic. 2009, 808, 129-132. [CrossRef]

15. Vardi, Y.; Reuveni, M. Antifungal activity of a new broad spectrum bio-fungicide in the controlling of plant diseases. Phytopathology 2009, 99, S134. 
16. Martillo, E.; Reuveni, M. A new potent bio-fungicide for the control of Banana Black Sigatoka. Phytopathology 2009, 99, S80.

17. Reuveni, M.; Neifeld, D. Timorex Gold-A novel organic fungicide for the control of plant diseases and black Sigatoka in banana. Acta Hortic. 2011, 811, 129-132.

18. Reuveni, M.; Sanches, E.; Barbier, M.R.F. Mode of activity of Timorex Gold against black Sigatoka. In Proceedings of the 4th International Banana Congress, San Jose, Costa Rica, 20-24 February 2010.

19. Karnovsky, M.J. A formaldehyde-glutaraldehyde fixative of high osmolarity for use in electron microscopy. J. Cell Biol. 1965, 27, 137A.

20. Salle, G.; Pichard, V.; Mourichon, X. Cytological study of the interaction between Mycosphaerella fijiensis Morelet and three cultivars of Musa presenting different levels of resistance. In Proceedings of the Sigatoka Leaf Spot Diseases of Bananas: Proceedings of an International Workshop, San Jose, Costa Rica, 28 March-1 April 1989; pp. 189-190.

21. Vasquez, N.; Tapia, A.C.; Galindo, J.J. Ultrastructural studies of the infection process of Mycosphaerella fijiensis on Musa cultivars. In Proceedings of the Annual Meeting ACORBAT, San Jose, Costa Rica, 28 March-1 April 1989; pp. 191-200.

22. Reuveni, M.; Neifeld, D. Timorex Gold-A novel organic fungicide for the control of plant diseases and Black Sigatoka in banana. In Proceedings of the 3rd Science Conference, Namyangju, Korea, 28 September-1 October 2011; pp. 526-529.

23. Koller, W.; Scheinpflug, H. Fungal resistance to sterol biosynthesis inhibitors: A new challenge. Plant Dis. 1987, 71, 1066-1074. [CrossRef]

24. Adams, D.J. Fungal cell wall chitinases and glucanases. Microbiology 2004, 150, 2029-2035. [CrossRef]

25. Bowman, S.M.; Free, S.J. The structure and synthesis of the fungal cell wall. BioEssays 2006, 28, 799-808. [CrossRef]

26. Reuveni, M.; Agapov, V.; Reuveni, R. Suppression of cucumber powdery mildew Sphaerotheca fuliginea by foliar sprays of pbospbate and potassium salts. Plant Pathol. 1995, 44, 31-39. [CrossRef]

27. Homma, Y.; Arimoto, Y. Mechanisms of plant disease control by potassium bicarbonate. In Proceedings of the 17th International Congress on Pesticide Chemistry, Hamburg, Germany, 5-10 August 1990; p. 94.

28. Soylu, E.M.; Kurt, S..; Soylu, S. In vitro and In Vivo antifungal activities of the essential oils of various plants against tomato grey mould disease agent Botrytis cinerea. Int. J. Food Microbiol. 2010, 143, 183-189. [CrossRef] [PubMed]

29. Soylu, E.M.; Soylu, S.; Kurt, S. Antimicrobial activities of the essential oils of various plants against tomato late blight disease agent Phytophthora infestans. Mycopathologia 2006, 161, 119-121. [CrossRef] [PubMed]

(C) 2020 by the authors. Licensee MDPI, Basel, Switzerland. This article is an open access article distributed under the terms and conditions of the Creative Commons Attribution (CC BY) license (http://creativecommons.org/licenses/by/4.0/). 